\title{
Parâmetros de planta como indicadores do nível de nitrogênio na cultura do milho(1)
}

\author{
Gilber Argenta ${ }^{(2)}$, Paulo Regis Ferreira da Silva ${ }^{(2)}$, João Mielniczuk(3) e Clayton Giani Bortolini(2)
}

Resumo - Um indicador ideal deve reproduzir a relação do nível de nitrogênio (N) no sistema solo/planta, deve ser capaz de detectar a deficiência ou o excesso de $\mathrm{N}$, e ser de rápido diagnóstico para permitir a correção de sua deficiência ainda na própria estação de crescimento. O objetivo deste experimento foi de estudar a efíciência de alguns parâmetros da planta (teor e acúmulo de N, leitura correspondente ao teor de clorofila na folha, avaliada com o clorofilômetro, massa seca e área foliar) como indicadores do nível de $\mathrm{N}$ na planta de milho. Para isto, cinco experimentos foram conduzidos no Município de Eldorado do Sul, na região fisiográfica da Depressão Central do Estado do Rio Grande do Sul, no ano agrícola de 1998/1999. A leitura correspondente ao teor de clorofila na folha foi o indicador mais eficiente do nível de $\mathrm{N}$ em todos os estádios de desenvolvimento da planta de milho, com exceção do estádio de três a quatro folhas expandidas em um dos experimentos. Os fatores de correção utilizados para as leituras no medidor portátil de clorofila (peso específico, massa seca e área foliar da folha) não foram eficientes para aumentar a correlação entre as leituras efetuadas e o rendimento de grãos.

Termos para indexação: Zea mays, clorofila, área foliar, matéria seca, teor de nitrogênio, instrumento de medição.

\section{Plant parameters as indicators of nitrogen status in maize crop}

\begin{abstract}
The ideal indicator of crop nitrogen status should reproduce the relationship of the nitrogen $(\mathrm{N})$ level in the crop and soil system, it must be able to detect deficiency or excess of $\mathrm{N}$ and it must be a fast diagnosis to allow correction in the same growing season. The objective of this experiment was to evaluate the efficiency of some plant parameters (nitrogen content and accumulation, leaf chlorophyll content, evaluated by the chlorophyll meter, dry matter and leaf area) as indicators of $\mathrm{N}$ level in the maize plant. Five experiments were conducted in the state of Rio Grande do Sul, Brazil, in the 1998/1999 growing season. The reading corresponding to the leaf chlorophyll content was the indicator that most accurately estimated the $\mathrm{N}$ level at all stages of development of the maize plant, with the exception of the stage of three to four expanded leaves in one of the experiments. The correction factors utilized for readings of the portable chlorophyll meter (specific weight, dry matter and leaf area) were not efficient in increasing the correlation between readings and grain yield.
\end{abstract}

Index terms: Zea mays, chlorophyll, leaf area, dry matter, nitrogen content, measuring instruments.

(1) Aceito para publicação em 28 de junho de 2001 . Extraído da tese de doutorado apresentada pelo primeiro autor à Universidade Federal do Rio Grande do Sul (UFRGS), Porto Alegre, RS. Parcialmente financiado pela Empresa Pioneer Sementes Ltda.

(2) UFRGS, Dep. de Plantas de Lavoura, Av. Bento Gonçalves, 7712, Caixa Postal 776, CEP 91540-000 Porto Alegre, RS. Bolsista do CNPq. E-mail: plantas@vortex.ufrgs.br, paulo.silva@vortex.ufrgs.br, bortolinic@zipmail.com

(3) UFRGS, Dep. de Solos. E-mail: mielniczuk@vortex.ufrgs.br

\section{Introdução}

Estima-se que a necessidade de $\mathrm{N}$ para produção de uma tonelada de grãos de milho varie de 20 a $28 \mathrm{~kg} \mathrm{ha}^{-1}$. A sua absorção pela planta ocorre durante todo o ciclo vegetativo, sendo pequena nos primeiros 30 dias. Nesta fase, as plantas absorvem menos do que $0,5 \mathrm{~kg} \mathrm{ha}^{-1} \mathrm{dia}^{-1}$ (Schröder et al., 2000). No entanto, a ocorrência de deficiência de $\mathrm{N}$ nos estádios iniciais de desenvolvimento da cultura re- 
duz o número de óvulos nos primórdios da espiga (Schreiber et al., 1988) e o crescimento e o desenvolvimento da planta (Varvel et al., 1997). Desta maneira, a adequada disponibilidade de $\mathrm{N}$ é importante durante todo o ciclo da cultura.

A maioria das recomendações de adubação nitrogenada para as culturas baseia-se na expectativa de rendimento de grãos e no teor de matéria orgânica do solo. Elas são fundamentadas na hipótese de que a matéria orgânica irá liberar $\mathrm{N}$ em tempo hábil para uso das plantas, além do $\mathrm{N}$ fornecido pelos fertilizantes, satisfazendo, assim, as necessidades das culturas (Amado, 1997). A utilização da matéria orgânica como parâmetro único para recomendar a adubação nitrogenada é insuficiente, pois, apesar de ser importante fonte de $\mathrm{N}$ para as plantas, é necessário que este nutriente seja liberado nas formas minerais $\left(\mathrm{NH}_{4}{ }^{+}\right.$e $\left.\mathrm{NO}_{3}{ }^{-}\right)$para absorção pelas plantas (Anghinoni, 1986). No solo, em torno de $95 \%$ do $\mathrm{N}$ está na forma orgânica (não disponível) e apenas 5\% na forma mineral (disponível) (Keeney, 1982). Além da quantidade de $\mathrm{N}$ limitada na matéria orgânica, outros processos importantes que governam o ciclo de $\mathrm{N}$ no solo são a mineralização e a imobilização (Argenta \& Silva, 1999). Assim, a quantidade de N que é disponibilizada para as plantas de milho a partir da matéria orgânica depende muito do ambiente, o qual altera a resposta do rendimento de grãos à aplicação de fertilizante nitrogenado.

Na maioria dos países em que a agricultura está em estágios mais avançados, o uso do teor de matéria orgânica do solo como parâmetro indicador do nível de $\mathrm{N}$ no sistema solo/planta durante a estação de cultivo está sendo substituído por outros que indicam o nível de $\mathrm{N}$ no solo, em plantas individuais e em comunidade de plantas. Entre os parâmetros de solo utilizados como indicadores do nível de $\mathrm{N}$ estão os testes de capacidade e de intensidade (Schröder et al., 2000). Os testes de capacidade levam em consideração, para estimar a disponibilidade de $\mathrm{N}$ parâmetros ambientais, o histórico da área e as propriedades do solo (Klausner et al., 1993). Já os testes de intensidade baseiam-se na quantidade de $\mathrm{N}$ mineral presente no solo, por meio de testes de présemeadura (Schröder et al., 2000), de pré-aplicação de $\mathrm{N}$ em cobertura (Binford et al., 1992), e de póscolheita (Sims et al., 1995).
Entre os parâmetros de planta mais utilizados como indicadores do nível de $\mathrm{N}$, estão a concentração de $\mathrm{NO}_{3}{ }^{-}$e a concentração de $\mathrm{N}$ total (Binford et al., 1992), e a intensidade da cor verde da folha. Este último pode ser determinado por meio de mensurações de refletância (Ma et al., 1996) e de absorção (Waskom et al., 1996; Sunderman et al., 1997; Varvel et al., 1997; Bullock \& Anderson, 1998; Argenta et al., 2001).

Os indicadores de solo e de planta acima relacionados referem-se a análises de solo e de planta. Para ambos, existem argumentos favoráveis e contrários. Em geral, parâmetros do solo predizem com maior segurança a quantidade de $\mathrm{N}$ a ser aplicada e, os da planta, a época de aplicação deste nutriente (Waskom et al., 1996; Sunderman et al., 1997; Schröder et al., 2000). Entre os parâmetros de planta, as medidas relacionadas à folha (massa seca, área foliar) e a intensidade de cor verde do dossel parecem ser mais adequadas para a decisão sobre a quantidade de $\mathrm{N}$ a ser aplicada em relação aos testes de $\mathrm{N}$ no tecido, devido à menor variação entre os valores obtidos (Schröder et al., 2000). Além disso, os testes que determinam o teor de $\mathrm{N}$ no tecido vegetal possuem a desvantagem de não possibilitar correção da deficiência deste nutriente no mesmo ano agrícola, sendo apenas úteis para identificar se houve falta ou excesso desse nutriente em um determinado estádio de desenvolvimento.

O objetivo deste trabalho foi o de estudar a eficiência do uso de alguns parâmetros de planta como indicadores do nível de $\mathrm{N}$ na cultura do milho.

\section{Material e Métodos}

Cinco experimentos foram conduzidos no campo da Estação Experimental Agronômica da Universidade Federal do Rio Grande do Sul, localizada no Município de Eldorado do Sul, região fisiográfica da Depressão Central, do Estado do Rio Grande do Sul, no ano agrícola 1998/1999. O clima da região é classificado, segundo Köppen, como subtropical úmido, situado na transição entre os tipos fundamentais $\mathrm{cfa}_{1}$ (isoterma anual inferior a $18^{\circ} \mathrm{C}$ ) e $\mathrm{cfa}_{2}$ (isoterma anual superior a $18^{\circ} \mathrm{C}$ ). As temperaturas médias anual, máxima e mínima, são de $19,6,24,3$ e $14,8^{\circ} \mathrm{C}$, respectivamente. O solo da área experimental é classificado como Argissolo Vermelho Distrófico típico (Embrapa, 1999). 
No experimento I, os tratamentos constaram de dois genótipos de milho (Pioneer 32R21 e Cargill 901), ambos híbridos simples e de ciclo superprecoce, e de nove níveis de $\mathrm{N}$ aplicados em cobertura $(0,50,100,150,200,300$, 400,500 e $600 \mathrm{~kg} \mathrm{ha}^{-1} \mathrm{de} \mathrm{N}$ ). Os híbridos foram estabelecidos em sistema de semeadura direta em sucessão à ervilhaca comum, com espaçamento entre linhas de $0,7 \mathrm{~m}$ e densidade de 65.000 plantas ha ${ }^{-1}$. A adubação nitrogenada em cobertura foi parcelada em quatro doses iguais, de acordo com os níveis estabelecidos. A primeira, segunda, terceira e quarta aplicações foram realizadas, respectivamente, nos estádios de três a quatro folhas, seis a sete folhas, 10 a 11 folhas e 14 a 15 folhas completamente desenvolvidas.

No experimento II, os tratamentos constaram de dois níveis de irrigação (adequado, próximo à capacidade de campo, e com excesso, $50 \%$ acima da capacidade de campo) e sete sistemas de manejo da adubação nitrogenada (0-30-0, 150-30-0, 75-30-75, 0-30-150, 60-30-0, 30-30-30 e 0-30-60, em que o primeiro, o segundo e o terceiro números, em cada sistema, referem-se, respectivamente, às doses de $\mathrm{N}\left(\mathrm{kg} \mathrm{ha}^{-1}\right)$ aplicadas no milho em pré-semeadura, ou seja, no momento da dessecação da cobertura do solo no inverno, na semeadura e em cobertura). O milho foi implantado em sistema de semeadura direta em sucessão à aveia-preta. O híbrido Braskalb XL 214, híbrido simples, precoce, foi semeado no espaçamento entre linhas de $0,7 \mathrm{~m}$ e densidade de 62.000 plantas ha $^{-1}$. A adubação nitrogenada em cobertura foi parcelada em duas doses iguais, aplicadas nos estádios de quatro a cinco e de sete a oito folhas expandidas.

No experimento III, os tratamentos testados foram três níveis de $\mathrm{N}$ em milho $\left(0,60\right.$ e $\left.160 \mathrm{~kg} \mathrm{ha}^{-1} \mathrm{de} \mathrm{N}\right)$ e cinco sistemas de consórcios (100\% aveia-preta, $67 \%$ de aveia e $33 \%$ ervilhaca comum, $50 \%$ aveia e $50 \%$ ervilhaca, $33 \%$ aveia e $67 \%$ ervilhaca e $100 \%$ ervilhaca). O milho foi estabelecido em sistema de semeadura direta em sucessão às diferentes coberturas. O híbrido Pioneer 32R21 foi semeado no espaçamento entre linhas de $0,7 \mathrm{~m}$ e densidade de 65.000 plantas $a^{-1}$. A adubação nitrogenada em cobertura foi parcelada em duas doses iguais, aplicadas nos estádios de quatro a cinco e de sete a oito folhas expandidas.

No experimento IV, testaram-se cinco sistemas de culturas que antecederam ao milho (consórcio aveia-preta e ervilhaca comum, aveia, consórcio aveia e ervilhaca no inverno e caupi no verão, lab lab e pousio invernal) e dois níveis de $\mathrm{N}$ em milho ( 0 e $\left.180 \mathrm{~kg} \mathrm{ha}^{-1}\right)$. O milho foi implantado em sistema de semeadura direta em sucessão. O híbrido Pioneer 3069, híbrido simples modificado, superprecoce, foi semeado no espaçamento entre linhas de $0,7 \mathrm{~m}$ e densidade de 60.000 plantas ha- ${ }^{-1}$. A adubação nitrogenada em cobertura foi parcelada em duas doses iguais, aplicadas nos estádios de quatro a cinco e de sete a oito folhas expandidas.

No experimento $V$, os tratamentos constaram de três sistemas de preparo de solo (reduzido, sem preparo e convencional) e três sistemas de cobertura de solo que antecederam ao milho (aveia-preta, ervilhaca comum e consórcio aveia e ervilhaca). O híbrido Pioneer 3069 foi semeado no espaçamento entre linhas de $0,7 \mathrm{~m}$ e densidade de 60.000 plantas ha $^{-1}$. A adubação nitrogenada em cobertura foi parcelada em duas doses iguais, aplicadas nos estádios de quatro a cinco e de sete a oito folhas expandidas.

No experimento I, as determinações realizadas foram: leitura correspondente ao teor de clorofila na folha, avaliada com o equipamento modelo Minolta SPAD-502, produção de massa seca por planta e folha avaliada, teor de $\mathrm{N}$ total no tecido e quantidade de $\mathrm{N}$ acumulada por planta $\mathrm{e}$ folha avaliada. Estas determinações foram realizadas nos estádios de três a quatro folhas, seis a sete folhas e de 10 a 11 folhas completamente desenvolvidas e no espigamento, utilizando-se cinco plantas por subparcela. Nos estádios vegetativos, as leituras com medidor de clorofila foram realizadas na penúltima e na última folhas totalmente expandidas. No estádio de espigamento, as leituras foram realizadas na folha-índice (primeira abaixo da espiga)

As leituras efetuadas com medidor de clorofila (duas por folha) foram feitas em pontos situados na metade a dois terços do comprimento da folha, a partir da base, e a $2 \mathrm{~cm}$ da margem da folha. As folhas em que foram realizadas as leituras foram coletadas em separado do resto da planta para determinação do peso específico, teor e acúmulo de $\mathrm{N}$ e da área foliar.

A determinação do peso específico seguiu o método proposto por Chapman \& Barreto (1997). As produções de massa seca por planta e por folha avaliadas foram determinadas nos estádios de três a quatro folhas, seis a sete folhas e de 10 a 11 folhas completamente desenvolvidas de milho e de espigamento, utilizando-se, respectivamente, cinco plantas e cinco folhas por subparcela. As plantas e as folhas em que foram realizadas as leituras foram secadas em estufa a $60^{\circ} \mathrm{C}$ até atingir peso constante. A quantidade de massa seca das amostras foi dividida por cinco, obtendo-se a produção de massa seca por planta e por folha avaliada. $\mathrm{O}$ teor de $\mathrm{N}$ foi determinado de acordo com o método descrito em Tedesco et al. (1995). As quantidades de $\mathrm{N}$ acumuladas por planta e por folha avaliada foram calculadas multiplicando-se, respectivamente, a massa seca por planta e da folha avaliada pelo seu teor de nitrogênio. $\mathrm{O}$ teor de $\mathrm{N}$ e a quantidade de $\mathrm{N}$ acumulada na 2 a folha não foram determinados, devido à pequena quantidade de material disponível. A área foliar foi obtida por meio da fór- 
mula $\mathrm{A}=\mathrm{C} * \mathrm{~L} * 0,75$ em que $\mathrm{C}$ representa o comprimento, e L, a largura da folha. $\mathrm{O}$ rendimento de grãos foi estimado por meio da extrapolação da produção colhida na área útil das subparcelas de um hectare, corrigindo-se a umidade para $130 \mathrm{~g} \mathrm{~kg}^{-1}$.

Nos experimentos II, III, IV e V foram avaliados: as leituras correspondentes ao teor de clorofila na folha com clorofilômetro, o teor de $\mathrm{N}$ na folha-índice e o peso específico da folha-índice, no estádio de espigamento, e o rendimento de grãos, por ocasião da colheita.

Os dados obtidos foram submetidos à análise de variância. Fez-se análise de correlação linear simples entre todas as variáveis avaliadas

\section{Resultados e Discussão}

No experimento I, a análise de correlação simples evidenciou que apenas no estádio de três a quatro folhas expandidas as leituras no clorofilômetro não se correlacionaram com rendimento de grãos de milho (Tabelas 1, 2 e 3). Neste estádio, a variável que apresentou maior coeficiente de correlação com rendimento de grãos foi o teor de $\mathrm{N}$ da 3 a folha da planta. Nos estádios de seis a sete folhas e de 10 a 11 folhas expandidas, a leitura SPAD efetuada, respectivamente, na $6^{\underline{a}}$ e $9^{\mathrm{a}}$ folhas, foi o parâmetro que apresentou maior correlação com rendimento de grãos. No estádio de espigamento, o teor de $\mathrm{N}$ da folha índice foi a variável que esteve mais associada com rendimento de grãos, seguida pela leitura efetuada pelo clorofilômetro.

No experimento II, houve maior correlação entre teor de $\mathrm{N}$ da folha índice e rendimento de grãos do que entre leitura no clorofilômetro e rendimento de grãos (Tabela 4). Nos experimentos III, IV e V, a análise de correlação simples no estádio de espigamento do milho evidenciou que as leituras com medidor portátil de clorofila estiveram mais associadas ao rendimento de grãos do que o teor de $\mathrm{N}$ da folha-índice.

Esses resultados evidenciam que, com exceção do estádio de três a quatro folhas expandidas de milho (experimento I) e no estádio de espigamento (experimento II), a leitura no clorofilômetro foi o indicador que esteve mais correlacionado com rendimento de grãos. Esta resposta pode estar associada ao fato de as leituras efetuadas pelo clorofilômetro não serem influenciadas pelo consumo de luxo de $\mathrm{N}$ sob forma de nitrato (Blackmer \& Schepers, 1994). $\mathrm{O}$ consumo de luxo resulta concentração de $\mathrm{N}$ na planta bem acima do nível adequado e influencia negativamente a correlação deste parâmetro com rendimento de grãos. Pelo fato de não ser influenciada pelo consumo de luxo de $\mathrm{N}$, a medição efetuada pelo clorofilômetro é considerada melhor indicadora do nível de $\mathrm{N}$ na planta do que o próprio teor deste nutriente (Blackmer \& Schepers, 1994).

As leituras no clorofilômetro apresentaram alta relação $\left(\mathrm{R}^{2}=0,81^{*}\right)$ com o rendimento de grãos de milho, sendo esta similar à verificada entre teor de $\mathrm{N}$ na folha-índice com rendimento de grãos de milho $\left(\mathrm{R}^{2}=0,83 *\right)$ (Figura 1). Este resultado evidencia que o teor relativo de clorofila na folha de milho está altamente associado com o rendimento de grãos e que pode substituir a determinação do teor de $\mathrm{N}$ na folha para diagnóstico do nível deste nutriente na planta.

Os demais parâmetros da planta de milho avaliados no experimento I, como massa seca por planta e por folha avaliada, área foliar e quantidade de $\mathrm{N}$ acumulado por planta e por folha avaliada apresentaram menores coeficientes de correlação com rendimento de grãos em relação aos obtidos entre leitura SPAD ou teor de $\mathrm{N}$ e rendimento de grãos, nos quatro está-

Tabela 1. Análise de correlação simples (r) entre as variáveis avaliadas no estádio de três a quatro folhas completamente desenvolvidas de milho, no experimento I. Eldorado do Sul, RS, 1998/1999.

\begin{tabular}{|c|c|c|c|c|c|c|c|c|c|c|c|c|}
\hline \multirow[t]{2}{*}{ Variáveis } & \multicolumn{2}{|c|}{ Leitura SPAD $^{(1)}$} & \multicolumn{3}{|c|}{ Peso seco } & \multicolumn{2}{|c|}{ Área } & \multicolumn{3}{|c|}{ Porcentagem de $\mathrm{N}$} & \multicolumn{2}{|c|}{ Acúmulo de $\mathrm{N}$} \\
\hline & $2^{\mathrm{a}}$ folha & $3^{\mathrm{a}}$ folha & Planta & $2^{\mathrm{a}}$ folha & $3^{\mathrm{a}}$ folha & $2^{\mathrm{a}}$ folha & $3^{\mathrm{a}}$ folha & $3^{\mathrm{a}}$ folha & Resto da planta & Planta & $3^{\mathrm{a}}$ folha & Total da planta \\
\hline Rendimento de grãos & ns & ns & $-0,31 *$ & $-0,33$ & $-0,33$ & $-0,24$ & ns & 0,34 & 0,26 & 0,30 & ns & ns \\
\hline Leitura SPAD ( $2^{a}$ folha $)$ & - & 0,53 & 0,39 & ns & ns & $\mathrm{ns}$ & ns & ns & ns & ns & ns & 0,43 \\
\hline Leitura SPAD ( $3^{\mathrm{a}}$ folha) & - & - & 0,27 & ns & ns & $\mathrm{ns}$ & ns & $\mathrm{ns}$ & ns & ns & ns & 0,29 \\
\hline
\end{tabular}

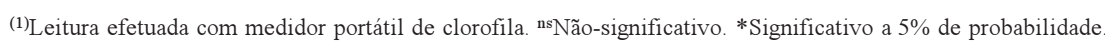


dios avaliados (Tabelas 1, 2 e 3 ). Isto evidencia que estes parâmetros de planta não foram bons indicadores do nível de $\mathrm{N}$ nas plantas.

A relação entre teor de $\mathrm{N}$ na folha e rendimento de grãos de milho é bem conhecida (Waskom et al., 1996). No entanto, este parâmetro de planta, além de ser influenciado pelo consumo de luxo de $\mathrm{N}$ e de envolver determinação laboratorial, apresenta a grande desvantagem de não possibilitar a correção de sua deficiência na planta no mesmo ano agrícola, devido ao tempo despendido entre a coleta e o resultado final, servindo apenas como parâmetro indicativo para os próximos cultivos.

Neste sentido, o parâmetro de planta que envolve a determinação da intensidade de cor da folha (absorbância), por meio do medidor portátil de clorofila, apresenta algumas vantagens sobre os demais: a leitura pode ser realizada em poucos minutos, possibilitando rápido diagnóstico da situação da lavoura; o aparelho tem custo mínimo de manutenção, ao contrário de outros testes que exigem a compra sistemática de produtos químicos; não há necessidade de envio de amostras para laboratório, economizando-se, portanto, tempo e dinheiro; e o agricultor pode realizar quantas amostras desejar, sem implicar a destruição das folhas (Malavolta et al., 1997).

A maior limitação da utilização do clorofilômetro, como indicador do nível de $\mathrm{N}$ em milho, é que ele não prediz com precisão a quantidade de $\mathrm{N}$ suplementar que deverá ser aplicada (Waskom et al., 1996; Sunderman et al., 1997). Por outro lado, os indicadores de solo não predizem com segurança quando este nutriente deverá ser aplicado (Schröder et al., 2000). Assim, evidencia-se a necessidade de se integrar o uso de indicadores do nível de $\mathrm{N}$ do solo e da planta para aumentar a precisão da recomendação de adubação nitrogenada em milho.

O teor de clorofila na folha correlaciona-se positivamente com teor de N na planta (Schadchina \& Dmitrieva, 1995; Waskom et al., 1996). Esta relação é atribuída principalmente ao fato de 50 a $70 \%$ do $\mathrm{N}$ total das folhas ser integrante de enzimas (Chapman \& Barreto, 1997) que estão associadas aos cloroplastos (Stoking \& Ongun, 1962). Os resultados do presente trabalho revelaram que as leituras no clorofilômetro correlacionaram-se positivamente com teor de $\mathrm{N}$ nas folhas, em todos os experimentos, com 
exceção da avaliação realizada no estádio de três a quatro folhas expandidas no experimento I, em que a correlação não foi significativa (Tabelas 1, 2, 3 e 4). A falta de associação entre teor de $\mathrm{N}$ e leitura SPAD neste estádio inicial de desenvolvimento da planta pode estar associada, provavelmente, ao fato de as plantas terem apresentado consumo de luxo de $\mathrm{N}$, devido à alta contribuição de $\mathrm{N}$ dos resíduos da ervilhaca comum, que antecedeu ao milho neste experimento. Smeal \& Zhang (1994), Waskom et al. (1996) e Bullock \& Anderson (1998) também verificaram baixa correlação entre a leitura correspondente ao teor de clorofila na folha e rendimento de grãos nos estádios iniciais de desenvolvimento da planta de milho.

No experimento I os coeficientes de correlação entre rendimento de grãos e as demais variáveis avaliadas foram inferiores aos obtidos nos demais experimentos (Tabelas 1, 2, 3 e 4). Esta diferença pode ser atribuída, principalmente, ao menor número de pon- tos obtidos e à pequena amplitude verificada entre os valores de rendimento de grãos $\left(9,2\right.$ a $\left.12,9 \mathrm{t} \mathrm{ha}^{-1}\right)$ e demais variáveis avaliadas no experimento I (Dixon \& Massey, 1957).

Para contornar a limitação da pequena amplitude verificada entre valores de leitura SPAD e, também, para corrigir o efeito de outros fatores que influenciam o teor de clorofila, tem sido sugerida como fator de correção a utilização do peso específico da folha (Chapman \& Barreto, 1997). Outros parâmetros também podem ser utilizados como fatores de correção, desde que estejam associados ao desenvolvimento da planta, como, por exemplo, massa seca e área foliar. No experimento I, a utilização dos fatores de correção como peso específico das folhas, massa seca e área foliar não resultou em aumento dos coeficientes de correlação entre leituras no clorofilômetro e rendimento de grãos (Tabela 5). Estes resultados indicam que, no presente trabalho, a leitura no clorofilômetro não foi afetada por outras variáveis, e

Tabela 3. Análise de correlação simples (r) entre as variáveis avaliadas no estádio de espigamento de milho, no experimento I. Eldorado do Sul, RS, 1998/1999.

\begin{tabular}{|c|c|c|c|c|c|c|c|c|c|}
\hline \multirow[t]{2}{*}{ Variáveis } & \multirow{2}{*}{$\begin{array}{l}\text { Leitura } \\
\text { SPAD } \\
\text { na folha- } \\
\text { índice }^{(1)}\end{array}$} & \multicolumn{2}{|c|}{ Peso seco } & \multirow{2}{*}{$\begin{array}{c}\text { Área } \\
\text { foliar da } \\
\text { folha- } \\
\text { índice }\end{array}$} & \multicolumn{3}{|c|}{ Porcentagem de $\mathrm{N}$} & \multicolumn{2}{|c|}{ Acúmulo de $\mathrm{N}$} \\
\hline & & Planta & $\begin{array}{l}\text { Folha- } \\
\text { índice }\end{array}$ & & $\begin{array}{l}\text { Folha- } \\
\text { índice }\end{array}$ & $\begin{array}{l}\text { Resto da } \\
\text { planta }\end{array}$ & $\begin{array}{c}\text { Total da } \\
\text { planta }\end{array}$ & $\begin{array}{l}\text { Folha- } \\
\text { índice }\end{array}$ & $\begin{array}{c}\text { Total da } \\
\text { planta }\end{array}$ \\
\hline Rendimento de grãos & $0,39^{*}$ & $\mathrm{~ns}$ & ns & ns & 0,43 & 0,35 & 0,35 & 0,37 & 0,35 \\
\hline Leitura SPAD na folha-índice & -- & 0,57 & 0,57 & 0,40 & 0,64 & 0,39 & 0,39 & 0,70 & 0,55 \\
\hline
\end{tabular}

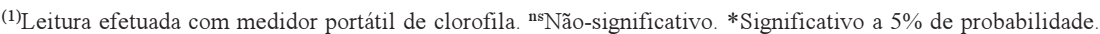

Tabela 4. Análise de correlação simples (r) entre as variáveis avaliadas na folha-índice no estádio de espigamento de milho nos experimentos II, III, IV e V. Eldorado do Sul, RS, 1998/1999.

\begin{tabular}{|c|c|c|}
\hline Variáveis & Leitura SPAD na folha-índice $^{(1)}$ & Porcentagem de $\mathrm{N}$ na folha-índice \\
\hline & \multicolumn{2}{|c|}{ Experimento II } \\
\hline Rendimento de grãos & $0,69 *$ & 0,73 \\
\hline \multirow[t]{2}{*}{ Leitura SPAD } & - & 0,78 \\
\hline & \multicolumn{2}{|c|}{ Experimento III } \\
\hline Rendimento de grãos & $0,80^{*}$ & 0,76 \\
\hline \multirow[t]{2}{*}{ Leitura SPAD } & - & 0,91 \\
\hline & \multicolumn{2}{|c|}{ Experimento IV } \\
\hline Rendimento de grãos & $0,87^{*}$ & 0,83 \\
\hline \multirow[t]{2}{*}{ Leitura SPAD } & - & 0,95 \\
\hline & \multicolumn{2}{|c|}{ Experimento $\mathrm{V}$} \\
\hline Rendimento de grãos & $0,93^{*}$ & 0,91 \\
\hline Leitura SPAD & - & 0,96 \\
\hline
\end{tabular}

${ }^{(1)}$ Leitura efetuada com medidor portátil de clorofila. * Significativo a $5 \%$ de probabilidade. 
que os três fatores de correção utilizados não foram eficientes para aumentar a amplitude dos valores verificados na leitura SPAD.

Por outro lado, Peng et al. (1993) concluíram que os efeitos de cultivar e de estádio de desenvolvi- mento da planta de arroz nas leituras do medidor de clorofila podem ser removidos simplesmente pela divisão do valor da leitura obtida pelo peso seco específico da folha (peso seco/área foliar), uma vez que ele está associado à espessura das folhas.

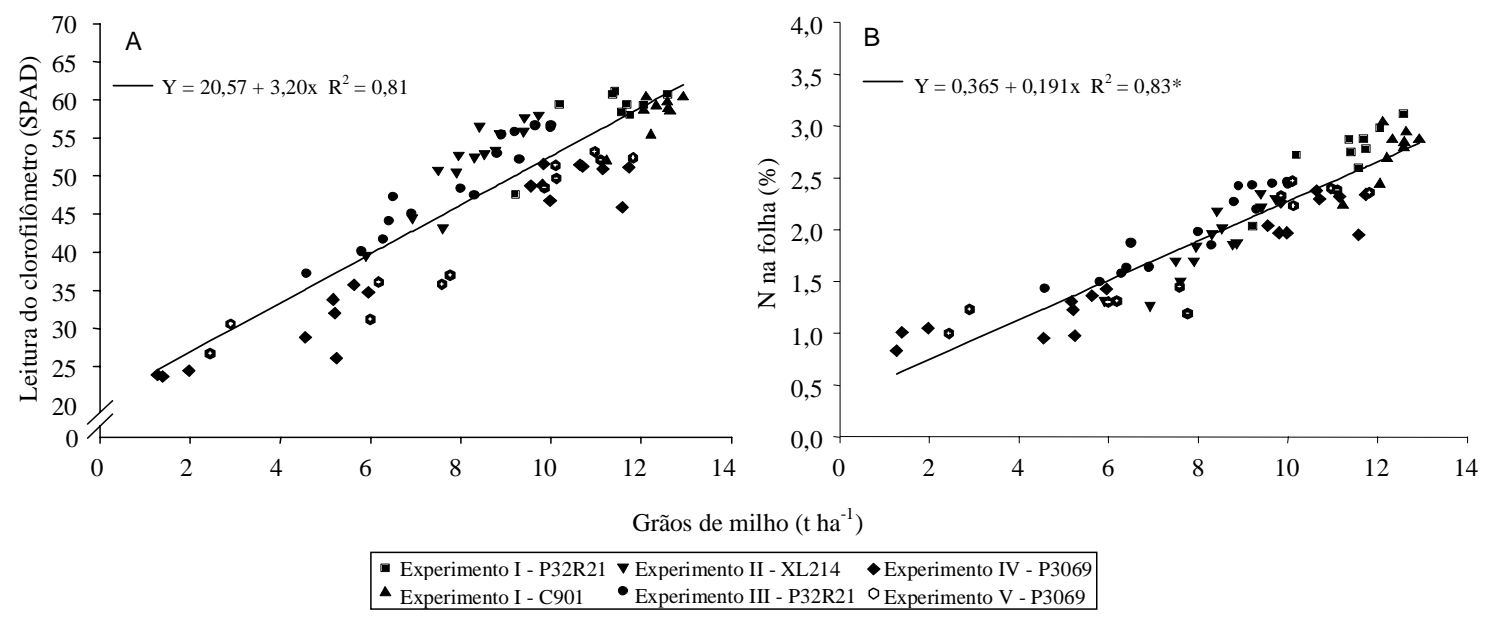

Figura 1. Relação da leitura do clorofilômetro e do teor de $\mathrm{N}$ na folha-índice com o rendimento de grãos de milho no estádio de espigamento, em cinco experimentos de milho. Eldorado do Sul, RS, 1998/1999. *Significativo a 5\% de probabilidade.

Tabela 5. Análise de correlação simples (r) entre rendimento de grãos e leitura no clorofilômetro corrigida pelo peso específico, pela massa seca e pela área foliar, nos estádios de três a quatro folhas, seis a sete folhas e 10 a 11 folhas expandidas e no de espigamento de milho, no experimento I. Eldorado do Sul, RS, 1998/1999.

\begin{tabular}{|c|c|c|c|c|c|}
\hline \multicolumn{6}{|c|}{ Estádio de três a quatro folhas } \\
\hline \multicolumn{2}{|c|}{ SPAD folha ${ }^{(1)} /$ peso específico } & \multicolumn{2}{|c|}{ SPAD folha/massa seca } & \multicolumn{2}{|c|}{ SPAD folha/área } \\
\hline $2^{\mathrm{a}}$ folha & $3^{\text {a }}$ folha & $2^{a}$ folha & $3^{a}$ folha & $2^{a}$ folha & $3^{a}$ folha \\
\hline $\mathrm{ns}$ & $\mathrm{ns}$ & $-0,33^{*}$ & $-0,33$ & $-0,24$ & ns \\
\hline \multicolumn{6}{|c|}{ Estádio de seis a sete folhas } \\
\hline \multicolumn{2}{|c|}{ SPAD folha ${ }^{(1)} /$ peso específico } & \multicolumn{2}{|c|}{ SPAD folha/massa seca } & \multicolumn{2}{|c|}{ SPAD folha/área } \\
\hline $5^{\mathrm{a}}$ folha & $6^{\mathrm{a}}$ folha & $5^{a}$ folha & $6^{\mathrm{a}}$ folha & $5^{\mathrm{a}}$ folha & $6^{a}$ folha \\
\hline $\mathrm{ns}$ & ns & ns & ns & ns & ns \\
\hline \multicolumn{6}{|c|}{ Estádio de 10 a 11 folhas } \\
\hline \multicolumn{2}{|c|}{ SPAD folha ${ }^{(1)} /$ peso específico } & \multicolumn{2}{|c|}{ SPAD folha/massa seca } & \multicolumn{2}{|c|}{ SPAD folha/área } \\
\hline $9^{\mathrm{a}}$ folha & $10^{\mathrm{a}}$ folha & $9^{a}$ folha & $10^{\mathrm{a}}$ folha & $9^{\mathrm{a}}$ folha & $10^{\mathrm{a}}$ folha \\
\hline $\mathrm{ns}$ & $\mathrm{ns}$ & $0,35 *$ & 0,28 & ns & ns \\
\hline \multicolumn{6}{|c|}{ Estádio de espigamento } \\
\hline $\begin{array}{l}\text { SPAD fo } \\
\text { específic }\end{array}$ & $\begin{array}{l}\mathrm{e}^{(1)} / \text { peso } \\
\text { la-índice }\end{array}$ & $\begin{array}{r}\text { SPAD foll } \\
\text { da }\end{array}$ & $\begin{array}{l}\text { massa seca } \\
\text { lice }\end{array}$ & $\begin{array}{r}\text { SPAD f } \\
\mathrm{da}\end{array}$ & $\begin{array}{l}\text { ice/área } \\
\text { ice }\end{array}$ \\
\hline & & & & & \\
\hline
\end{tabular}

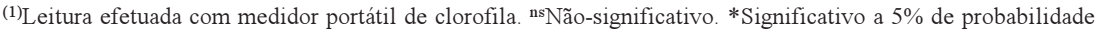


Chapman \& Barreto (1997) também verificaram no milho aumento na associação entre rendimento de grãos e leitura no clorofilômetro quando dividiram os valores das leituras efetuadas no medidor pelo peso específico da folha.

\section{Conclusões}

1. Dos parâmetros de planta testados, a leitura correspondente ao teor de clorofila da folha por meio do clorofilômetro é o indicador mais preciso do nível de nitrogênio em todos os estádios de desenvolvimento da planta de milho, com exceção do estádio de três a quatro folhas expandidas.

2. Os fatores de correção das leituras no medidor portátil de clorofila utilizados como peso específico, massa seca e área foliar, não são eficientes para aumentar a correlação entre leituras no clorofilômetro e rendimento de grãos de milho.

\section{Referências}

AMADO, T. J. C. Disponibilidade de nitrogênio para o milho em sistemas de cultura e preparo do solo. 1997. 201 f. Tese (Doutorado) - Universidade Federal do Rio Grande do Sul, Porto Alegre. 1997.

ANGHINONI, I. Adubação nitrogenada nos estados do Rio Grande do Sul e Santa Catarina. In: SANTANA, M. B. M. Adubação nitrogenada no Brasil. Ilhéus: Comissão Executiva do Plano da Lavoura Cacaueira/Sociedade Brasileira de Ciência do Solo, 1986. p. 1-18.

ARGENTA, G.; SILVA, P. R. F. da. Adubação nitrogenada em milho implantado em semeadura direta após aveia-preta. Ciência Rural, Santa Maria, v. 29, n. 4, p. 745-754, 1999

ARGENTA, G.; SILVA, P. R. F. da; BORTOLINI, C. G Teor de clorofila na folha como indicador do nível de $\mathrm{N}$ em cereais. Ciência Rural, Santa Maria, v. 31, n. 3, p. 715 722,2001

BINFORD, G. D.; BLACKMER, A. M.; MEESE, B. G Optimal concentrations of nitrate in cornstalks at maturity. Agronomy Journal, Madison, v. 84, n. 5, p. 881-887, 1992

BLACKMER, T. M.; SCHEPERS, J. S. Techniques for monitoring crop nitrogen status in corn. Communications in Soil Science and Plant Analysis, New York, v. 25, n. 9/10, p. 1791-1800, 1994.
BULLOCK, D. G.; ANDERSON, D. S. Evaluation of the Minolta SPAD 502 chlorophyll meter for nitrogen management in corn. Journal of Plant Nutrition, New York, v. 21, n. 4, p. 741-755, 1998.

CHAPMAN, S. C.; BARRETO, H. J. Using a chlorophyll meter to estimate specific leaf nitrogen of tropical maize during vegetative growth. Agronomy Journal, Madison, v. 89, n. 4, p. $557-562,1997$

DIXON, W. J.; MASSEY, F. J. Introduction to statistical analysis. New York: McGraw-Hill Book, 1957. 490 p.

EMBRAPA. Centro Nacional de Pesquisa de Solos (Rio de Janeiro, RJ). Sistema brasileiro de classificação de solos. Brasília, 1999. 412 p.

KEENEY, D. R. Nitrogen management for maximum efficiency and minimum pollution. In: STEVENSON, F. J. Nitrogen agriculture soils. Madison: Soil Science Society of America, 1982. p. 605-649

KLAUSNER, S. D.; REID, W. S.; BOULDIN, D. R. Relationship between late spring soil nitrate concentrations and corn yields in New York. Journal of Production Agriculture, Madison, v. 6, n. 2, p. 350-354, 1993.

MA, B. L.; MORRISON, M. J.; DWYER, L. M. Canopy light reflectance and field greenness to assess nitrogen fertilization and yield of maize. Agronomy Journal, Madison, v. 88, n. 6, p. 915-920, 1996.

MALAVOLTA, E.; VITTI, G. C.; OLIVEIRA, S. A. Avaliação do estado nutricional das plantas: princípios e aplicações. Piracicaba: Potafos, 1997. 319 p

PENG, S.; GARCÍA, F. V.; LAZA, R. C.; CASSMAN, K. G. Adjustment for specific leaf weight improves chlorophyll meter's estimate of rice leaf nitrogen concentration. Agronomy Journal, Madison, v. 85, n. 5, p. $987-990,1993$

SCHADCHINA, T. M.; DMITRIEVA, V. V. Leaf chlorophyll content as a possible diagnostic mean for the evaluation of plant nitrogen uptake from the soil. Journal of Plant Nutrition, New York, v. 18, n. 6, p. 1427-1437, 1995.

SCHREIBER, H. A; STANBERRY, C. O; TUCKER, H Irrigation and nitrogen effects on sweet corn row number at various growth stages. Science, Washington, v. 135, n. 1, p. $135-136,1988$.

SCHRÖDER, J. J.; NEETESON, J. J.; OENEMA, O.; STRUIK, P. C. Does the crop or the soil indicate how to save nitrogen in maize production? Reviewing the state of 
the art. Field Crops Research, Amsterdam, v. 66, n. 1, p. $151-164,2000$.

SIMS, J. T.; VASILAS, B. L.; GARTLEY, K. L.; MILLIKEN, B.; GREEN, V. Evaluation of soil and plant nitrogen tests for maize on manured soils of the Atlantic coastal plain. Agronomy Journal, Madison, v. 87, n. 2, p. 213-222, 1995.

SMEAL, D.; ZHANG, H. Chlorophyll meter evaluation for nitrogen management in corn. Communications in Soil Science and Plant Analysis, New York, v. 25, n. 9/10, p. 1495-1503, 1994.

STOKING, C. R.; ONGUN, A. The intracellular distribution of some metallic elements in leaves. American Journal of Botany, Columbus, v. 49, n. 3, p. 284-289, 1962.

SUNDERMAN, H. D.; PONTIUS, J. S.; LAWLESS, J. R. Variability in leaf chlorophyll concentration among fully- fertilized corn hybrids. Communications in Soil Science and Plant Analysis, New York, v. 28, n. 19, p. 1793-1803, 1997.

TEDESCO, M. J.; GIANELLO, C.; BISSANI, C. A. Análise de solo, plantas e outros materiais. 2. ed. Porto Alegre: UFRGS, 1995. 174 p. (Boletim Técnico de Solos, 5).

VARVEL, G. E.; SCHEPERS, J. S.; FRANCIS, D. D Ability for in-season correction of nitrogen deficiency in corn using chlorophyll meters. Soil Science Society of America Journal, Madison, v. 61, n. 4, p. 1233-1239, 1997.

WASKOM, R. M.; WESTFALL, D. G.; SPELLMAN, D. E.; SOLTANPOUR, P. N. Monitoring nitrogen status of corn with a portable chlorophyll meter Communications in Soil Science and Plant Analysis, New York, v. 27, n. 3, p. 545-560, 1996. 